\title{
BONE ANOMALIES OF THE TARSUS IN RELATION TO "PERONEAL SPASTIC FLAT FOOT"
}

\author{
F. A. JACK
}

Harris and Beath (1947) made a valuable contribution to surgery when they described for the first time the developmental anomaly at the sustentaculum tali-the talo-calcanean bridge-as an important and frequent element in the production of rigid flat foot. They also performed a further service by drawing attention to the hitherto rather neglected papers of Slomann (1921) and Badgley (1927). Both these authors described another congenital anomaly - the calcaneo-navicular bar-in association with so-called spastic flat foot, but their work went practically unheeded by their surgical colleagues. Seven years ago the etiology of peroneal spasm and rigid flat foot was still something of a mystery. Treatment was mainly empirical and usually unsuccessful. The fact that special radiological projections are required in order to reveal the anomalies is probably the reason for their prolonged obscurity.

In consequence of the stimulation of Harris and Beath's contribution, all patients with peroneal spasm or rigid flat foot, excluding those with rheumatoid arthritis, seen since 1949 have been made the subject of special study. This paper presents an analysis and discussion of the main features in thirty patients, twenty-seven of whom reported with the usual symptoms and signs. Three others reported for other reasons and, in the course of routine examination, were found to possess one or other of the bone anomalies. They have been included in order to further knowledge of the behaviour of these anomalies. For the sake of convenience the short descriptive terms suggested for these anomalies by Harris and Beath --the talo-calcanean bridge and the calcaneo-navicular bar-will be used throughout.

Since Harris and Beath's paper, a report has been published by Webster and Roberts (1951) on twenty-one patients with peroneal spasm or rigid flat feet, of whom tarsal anomalies were found in fourteen.

TABLE I

Incidence of Talo-Cai.caneal Bridge and Calcaneo-Navicular Bar in Sixty-eight Cases of Rigid Flat foot

\begin{tabular}{|c|c|c|c|c|c|}
\hline Author & $\begin{array}{l}\text { Number } \\
\text { of cases }\end{array}$ & $\begin{array}{c}\text { Talo-calcanean } \\
\text { bridge }\end{array}$ & $\begin{array}{c}\text { Calcaneo- } \\
\text { navicular bar }\end{array}$ & Both & $\begin{array}{c}\text { No bone } \\
\text { abnormality }\end{array}$ \\
\hline Harris and Beath & 17 & 12 & 3 & 0 & 2 \\
\hline Webster and Roberts & 21 & 4 & 8 & 2 & 7 \\
\hline Jack & 30 & 11 & 12 & 0 & 7 \\
\hline Totals & 68 & 27 & 23 & 2 & 16 \\
\hline
\end{tabular}

This series of thirty patients includes twenty-three who had one or other of the anomalies. Twelve patients had calcaneo-navicular bars (nine bilateral and three unilateral) and eleven had talo-calcanean bridges (three bilateral and eight unilateral). Only seven of the thirty presented no evidence of one or other anomaly. The cases are summarised in Table I, which shows that in the aggregate of the three series mentioned a bony anomaly was present in over three-quarters of the cases.

When Mr Jack died some months ago he left a lot of manuscript material about congenital anomalies of the foot which he had clearly intended to submit for publication. We are most grateful to Professor Walter Mercer and $\mathrm{Mr}$ James Scott for their endeavour in completing the contribution as Jack would have wished-and thus making so important a posthumous recognition.-FDIToR.] 
BONE ANOMALIES OF THE TARSL'S IN RELATION TO " PERONEAL SPASTIC FLAT FOOT" „),31

THE NATURE OF THE BONY ANOMALIES

The calcaneo-navicular bar and the talo-calcanean bridge are similar anatomical defects with similar developmental cause, so they may conveniently be considered together. Previous authors have fully described the physical appearance of these anomalies. In each case the tissue uniting the two main bones may be completely osseous (synostosis), or the bone may be

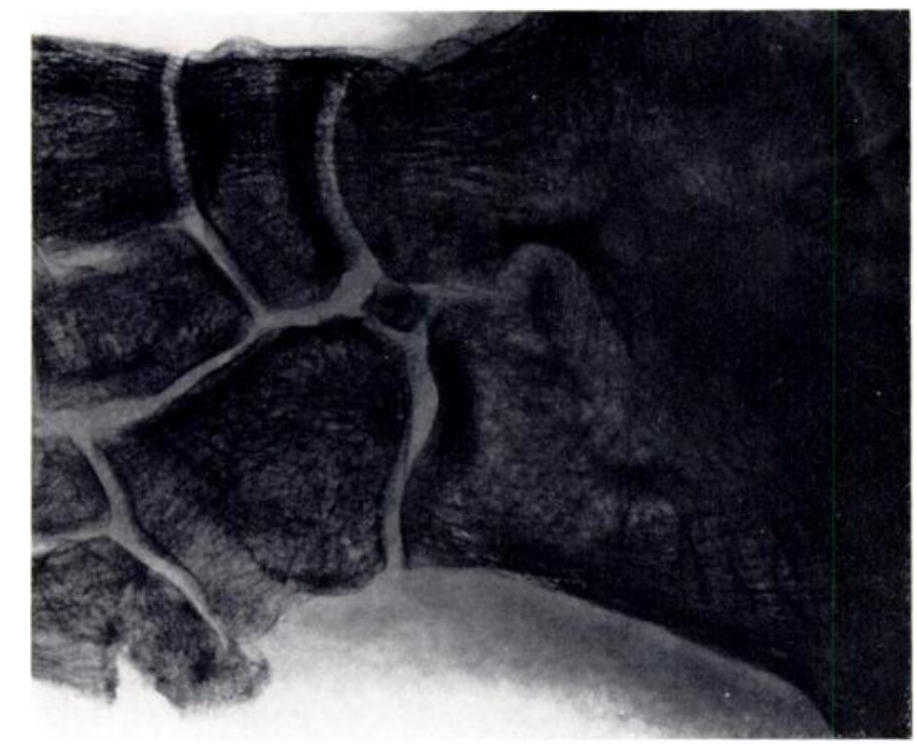

Fis; 1

()s calcanteum serondarium.

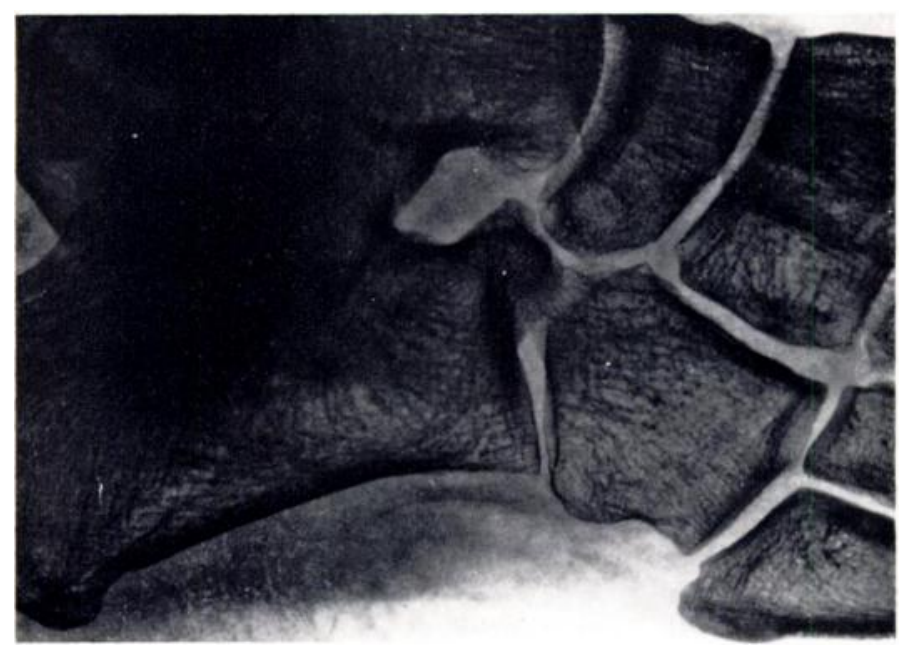

Fili. 2

Calcaneo-navicular bar of medium brealth with a wide fissure.

divided by a fissure of varying depth which may consist of cartilage (synchondrosis) or fibrous tissue (syndesmosis) (Figs. I to 9). The authors of most earlier papers quoted from the work of anatomists of fifty years or more ago, particularly that of Pfitzner, who described two small accessory bones occasionally found in each situation-the os sustentaculi and the calcaneum secundarium (Fig. 1). The tendency has been to consider that the accessory bone 
lies at the root of the trouble and that its fusion to one or other, or to both, of the main bones is the cause of the syndesmosis, synchondrosis or synostosis. This view is not entirely. acceptable and, although the argument is purely academic, comment is justified.

From the examples illustrated it is obvious that the bony processes vary considerably. in their nature and dimensions. A calcaneo-navicular bar may be a massive structure, well over an inch in width, and it may extend across to the medial side of the navicular bone. A talo-calcaneum bridge may also be wide, and it may involve the whole of the sustentaculum facet as well as the area behind it. Fissures may be oblique or central and they are not necessarily confined to one or other extremity of the bony bar. Radiographically, only a small proportion of the anomalies present anything to suggest that they are derived from an accessory bone that has fused on one side or the other.

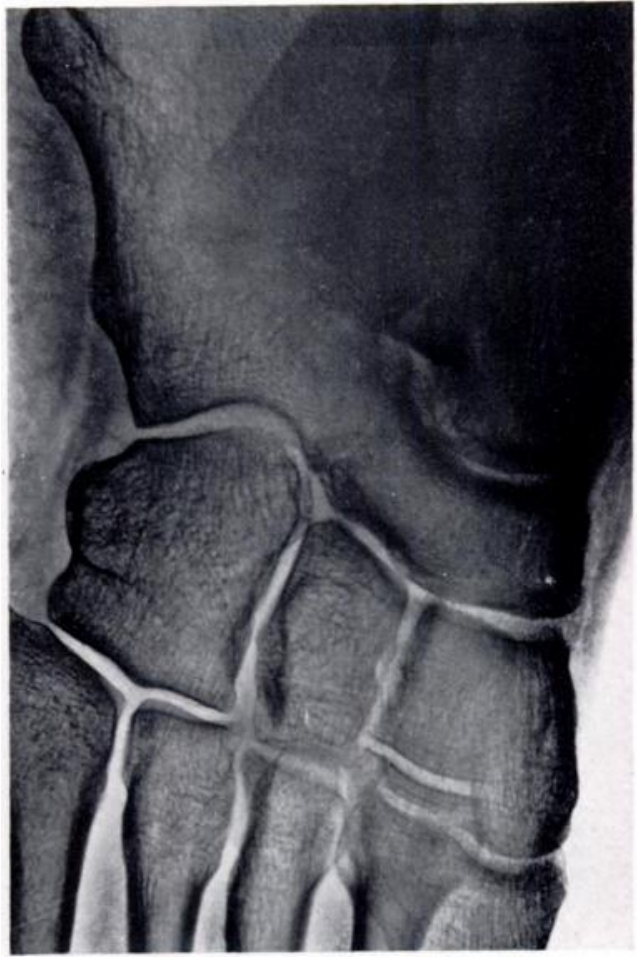

FIG. 3

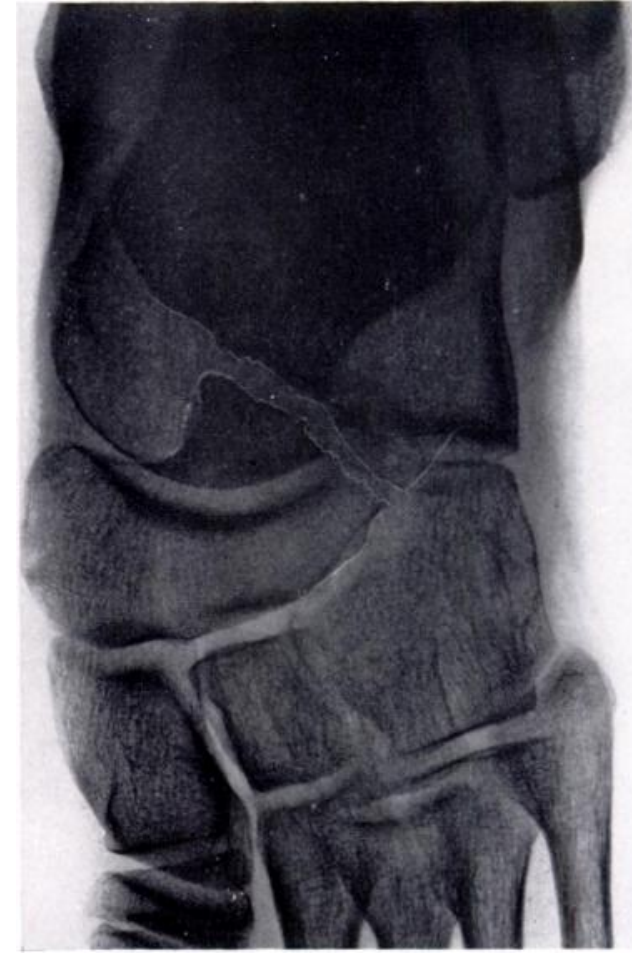

Fig. 4

Figure 3--Broad calcaneo-navicular bar seen in oblique view. Figure 4-Broad calcaneo-navicular bar seen in antero-posterior view demonstrating its width.

The origin of the abnormality goes back to the early differentiation of mesenchyme which is destined to form the tarsal region, to the laying down of pre-ligament and pre-cartilage tissue, and to primitive joint formation as a whole. An error in this differentiation (possibly. hereditary) may lead to a large complete bony fusion at one extreme, or to a small accessory bone at the other extreme. Both are variations in degree of the same anomaly.

Radiographic diagnosis - It is well known that the bony anomalies are difficult to detect in the routine antero-posterior and lateral projections of the foot, and that special oblique views of the foot and axial views of the heel are essential for diagnosis. The technique of these projections has been fully described elsewhere. One of the radiographic features which Harris and Beath emphasised particularly is the bone spur which forms on the dorsal and lateral side of the head of the talus. This spur formation is by no means diagnostic of a tarsal anomaly. It occurs in other conditions in which there has been long-standing valgus deformity 
at the midtarsal joint. In the present series of cases spurs were seldom found in the young patients, but became more constant after the age of sixteen. They tend to develop during adolescence in case's with severe persistent simptoms (Fig. I0), and in older patients with rigid eversion of the foot. Ther may become large, and, in fact, the whole navicular may become enlarged so that the naviculo-cuneiform joints are also spurred. In patients with

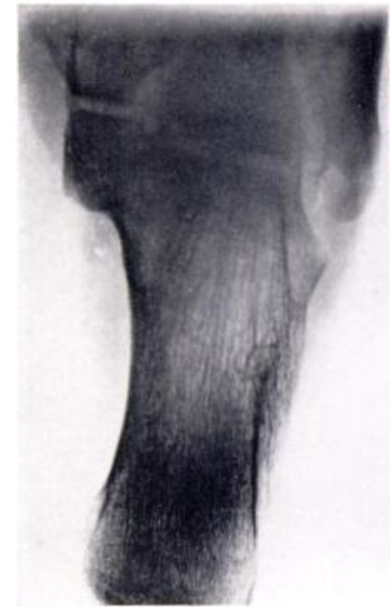

Hici. 5

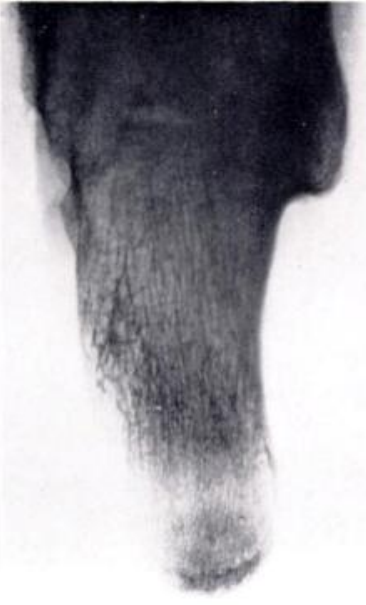

Fili, i

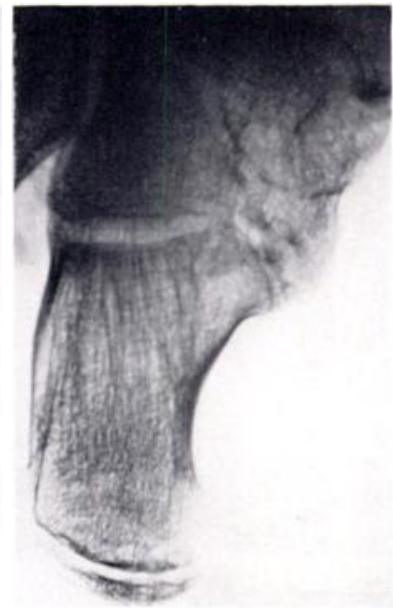

Fici. 7

Figure 5-Axial view of normal subtalar joint. Figure 6 - similar view of same patient's wher foot with complete talo-calcanean bridge. Figure 7 --Axial view of massive talo-calcancan bridge with an oblicfue fissure.

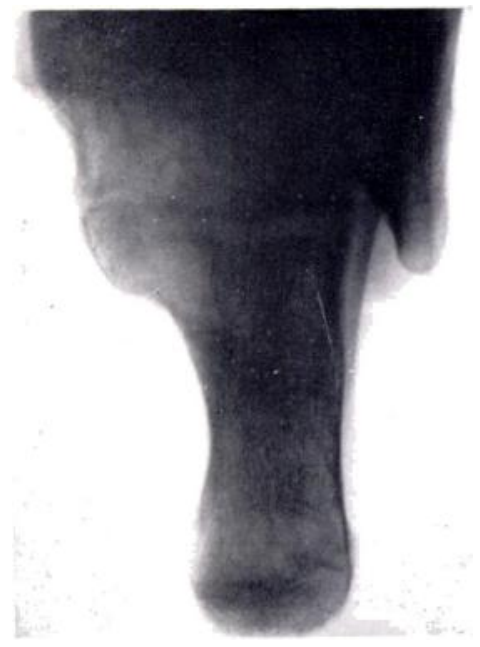

Fig. \&

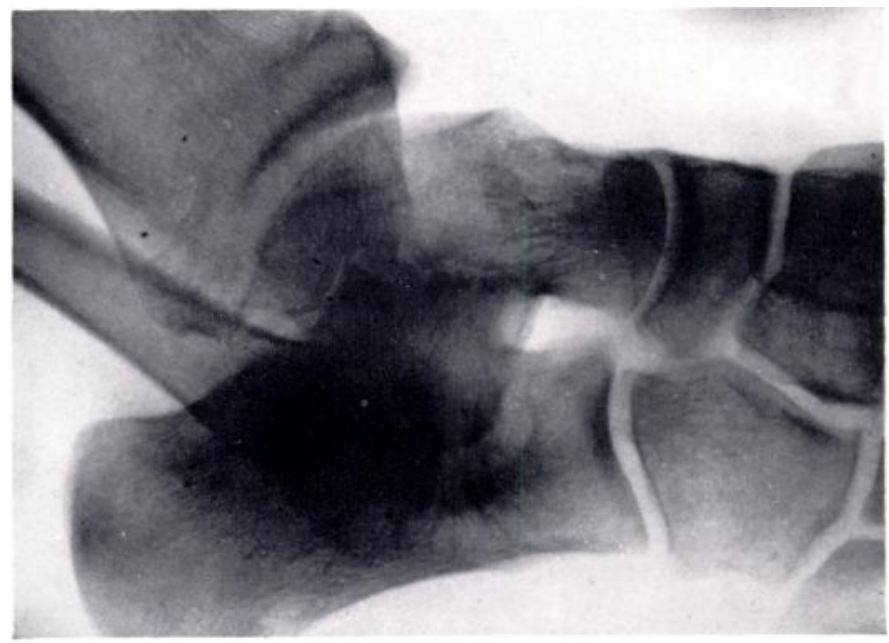

Fir;. 9

Figure 8- Axial view of massive talo-calcanean bridge with horizontal fissure. Figure 9- (Oblique virw of the same structure to show its width.

severe persistent spasm spurs may form not only on the supero-lateral aspect of the talus, but also on the supero-lateral aspect of the cuboid and calcaneum (Fig. 11).

\section{GLINICAL FEATURES}

Both anomalies produce rather similar symptoms and deformity although there are distinct variations in the severity and degree. A comparative analysis of the clinical features found in twent $y$-three cases is therefore instructive. For ease of reference, the leading features are summarised in Tables II and III.

VOL. $36 \mathrm{~B}$, NO. 4, NOVEMBLR 1954 
TABL.E II

Age at Onset and Period of Observation

\section{Calcaneo-navicular bar}

(12 patients: 9 bilateral, 3 unilateral-21 feet)

Age when first seen

$9,10,10,11,12,12,14,15,15,23,28,32$

Age at first symptoms

$9,11,8,11$, "childhood," no symptoms, $14,14,15,13,28,14$

Age at last review

$10,13,11,13,18,14,17,15,19,24,28,32$

Talo-calcaneal bridge

(11 patients: 3 bilateral, 8 unilateral-14 feet)

Age when first seen

$13,13,13,13,13,13,15,15,15,16,38$

Age at first symptoms

$13,13,12,12,8,13,13$, none, $15,16,15$

Age at last review

$18,16,18,20,16,14,19,16,15,18,38$

TABLE III

ANalysis of MaIn Symptons and Signs

(Numbers refer to feet)

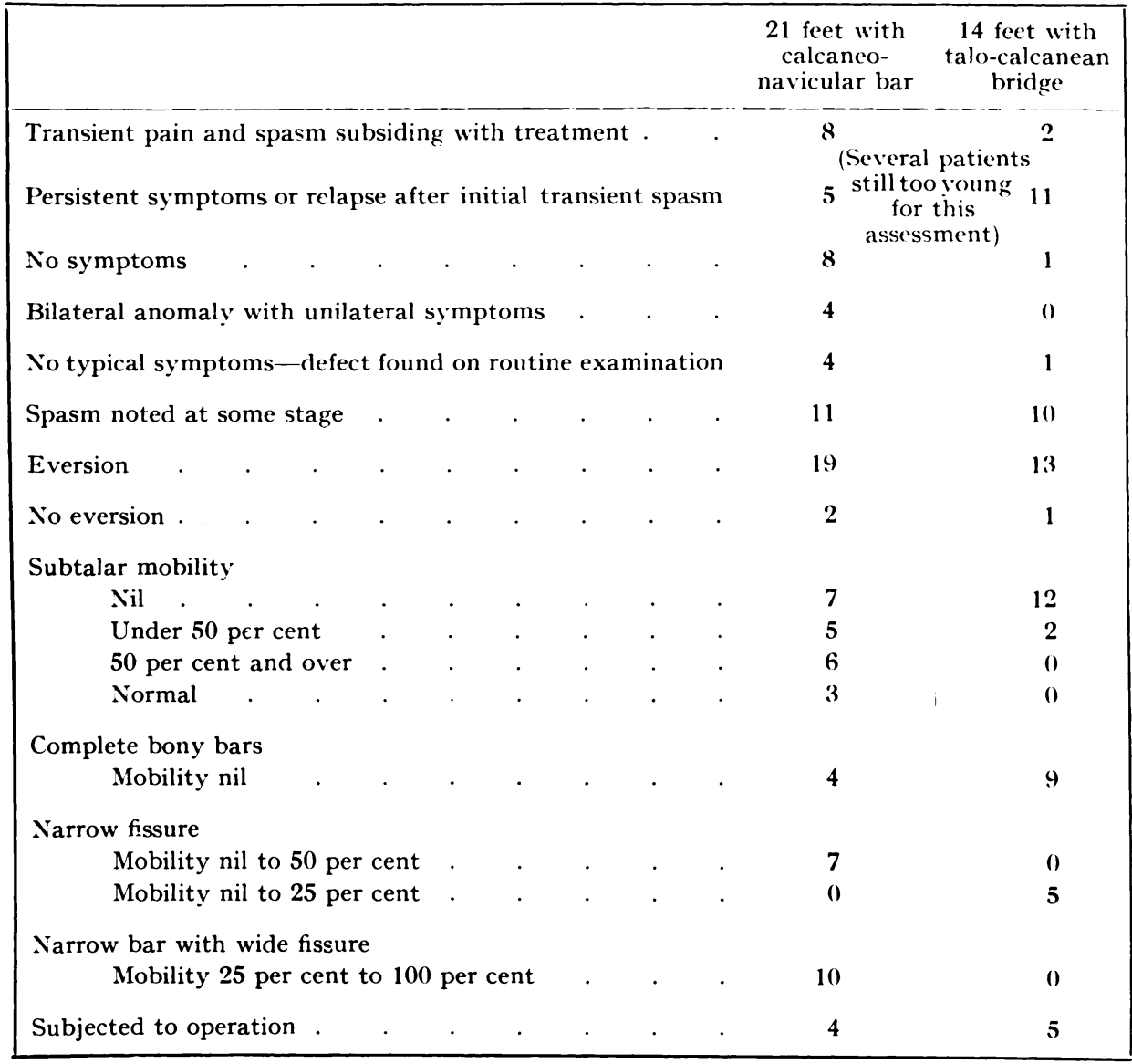


Age incidence-Although there is the odd patient in each group in whom symptoms started during early childhood, by far the commonest age at which children began to complain was between the ages of twelve and fifteen rears - that is, during the age of rapid ossification and bone growth. The calcaneo-navicular bar seems likely to produce symptoms at a slightly. earlier age than the talo-calcanean bridge. This may well be because the first anomaly involves the midtarsal joint, which is more liable to strain or trauma than the subtalar joint during normal childhood activities. The anomaly, too, is a much longer structure and therefore subject to much greater leverage.

Symptoms and signs - From the symptomatic viewpoint the patients in this series fall conveniently into three categories.

In the first category are those who complained originally of an acute incident of pain and peroneal spasm which settled permanently after treatment. In a high proportion of these patients there was a history of some minor injury a twist or a kick on the foot - shortly before the onset, though this was not a constant factor. Severe injury, sufficient to cause a

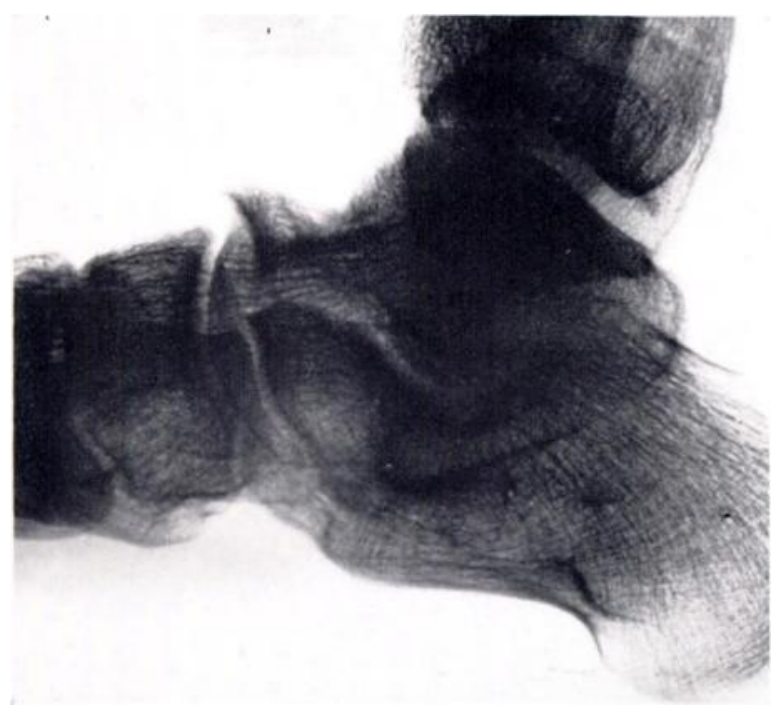

Fici. 10

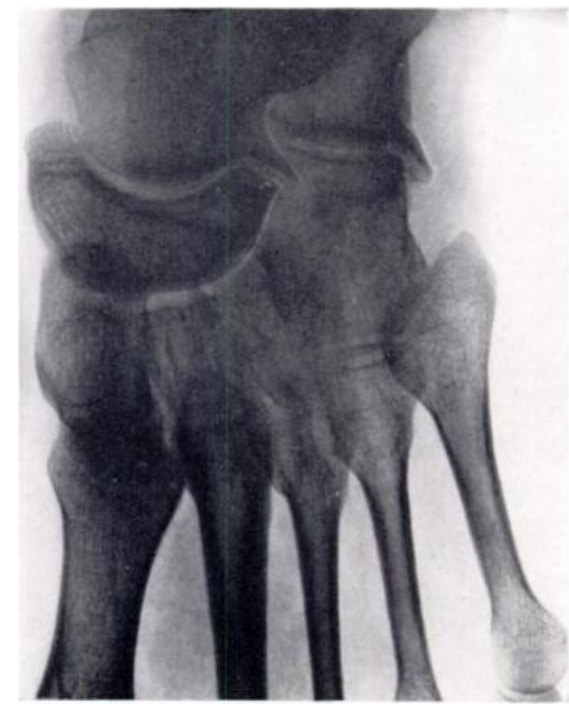

Fici. 11

Fierure 10 Spur on dorso-lateral aspect of the head of the talus associated with a tale-calcanean briclece Radiographs taken four years previously showed no such abnormality. Figure 11 - Spurs on supero-lateral aspect of calcaneum and cuboid associated with a talo-calcanean bridee.

fracture of a calcaneo-navicular bar or disruption of a fibrous fissure (Harris and Beath) hats never been encountered. Treated by relief from weight bearing either in bed or in a plaster for four to six weeks and thereafter by a course of physiotherapy, many of these patients lost their spasm and pain and were able to carry on without real disability despite some restriction of subtalar mobility and some eversion of the heel. This transient incident of spasm subsiding with treatment was commoner in patients with a calcaneo-navicular bar and was unusual in those with a talo-calcanean bridge.

In the second category were those who complained of chronic persistent pain and stiffness or who relapsed after an acute incident of spasm. These symptoms were much commoner in patients with a talo-calcanean bridge; eleven of the fourteen feet fell into this categors: Only five patients with calcaneo-navicular bars were in this category but the figure is probably. misleading because four of these patients had barely entered puberty and were too young for assessment. They may very well develop symptoms and disability later.

The third category comprises patients who have anomalies without symptoms. Only one patient with a talo-calcanean bridge came into this grading a boy of fifteen with bowed

V(I.. 36 B, No. 4, NOVLMHER 1954 
tibiae and compensatory valgus of both feet. The right heel was mobile, the left fixed by a typical bridge with a fissure. He plays all games and has never suffered pain or disability.

Eight feet with calcaneo-navicular bars were symptomless. Four of these were in bilateral cases in which only one foot was troublesome. The bar in the asymptomatic foot was of the narrow, poorly developed type with a wide fissure or possibly a joint across it. Slomann (1921) reported two such cases in his series of five. As is shown later, there is a distinct association between the size of the bar and the severity of the deformity and symptoms. In the remaining four feet (two patients) the bony anomaly was discovered on routine examination. One patient admitted to some trouble with the feet when he was fifteen. Thereafter he had served in the Army, doing normal marches and playing games without complaint. At thirty-two he served in a shop, standing all day. He reported complaining of a disorder of the knee and was discovered to have rigid eversion of both heels, with well developed calcaneo-navicular bars. The second patient reported at the age of twelve with mild hallux rigidus. There was some limitation of subtalar movement, and bilateral calcaneo-navicular bars with fissures were demonstrated. Three years later he was free from symptoms; he played tennis and other games and planned to join the Royal Air Force. The left subtalar joint had a quarter of the normal range and the right half. On the left side spurs were beginning to develop on both talus and cuboid. He may yet develop disability.

Spasm-True peroneal spasm, often also involving the extensor digitorum longus, was noted frequently at some stage during the course of observation, usually in the younger patients. The spasm could be relaxed by anaesthesia, or by a period of rest from weight bearing. In this series it occurred rather more commonly in the feet with talo-calcanean bridges-ten out of the fourteen feet, against eleven out of the twenty-one feet with calcaneo-navicular bars. Webster and Roberts (1951) noted it more often in the latter group and there is probably little difference between the two groups in a large series.

Eversion-Eversion of the heel, varying from a minor to a gross degree, was almost the rule, but with each anomaly there was that exception which makes the rule invalid. Slomann (1921) was mystified by one of his cases, that of a girl of ten years, who complained of acute pain in the foot after a minor injury. He found a complete calcaneo-navicular bar in a normally arched, well balanced foot, and was at a loss to explain the absence of deformity. The answer probably lay in the age of his patient.

In this series one patient with a complete talo-calcanean bridge reported at the age of fifteen with a minor attack of spasm and pain which yielded successfully to rest and physiotherapy. At the age of seventeen she undertook all normal activities and wore a high-heeled shoe most elegantly. She had no complaint except an occasional tendency to sprain her ankle on rough ground. The hind-foot was rigid but plantigrade.

Two feet with calcaneo-navicular bars presented no eversion at the heel. One belonged to a patient who had no symptoms at all until a mild sprain at the age of twenty-eight revealed the anomaly. The second was in a case that demonstrates well how careful observation over the whole period of childhood and adolescence is necessary before the true behaviour of these anomalies can be known. A young girl of ten came complaining of tiredness in both feet. Both feet were highly arched: the right heel was inverted and the left heel plantigrade. Subtalar movement was restricted on both sides. Radiographs showed bilateral calcaneonavicular bars, the right a slender one with a wide fissure, the left a rather broad bar with a narrow but well defined fissure (Figs. 12 and 13). At age eleven she had a transient attack of pain and spasm in the left foot which settled with treatment. Now, at age thirteen, the left foot is no longer cavus and the heel is everted. Radiographs show a broad bar on the left side with a fissure just visible. Spurring of the talar head has started. The right foot remains cavus and the heel remains inverted. There is still a wide central fissure across the bar on the right side. On both sides there has been considerable increase in the ossification of the bar and in its relative bulk. 
Subtalar mobility-As is to be expected, movement at the subtalar joint is nearly always abolished by a talo-calcancan bridge. Only two feet in this group had a trace of movement and in both instances there was a well defined fissure across the bony bridge. There mar, however, be quite a good range of movement in the presence of a calcaneo-navicular har if the bar is poorly developed.

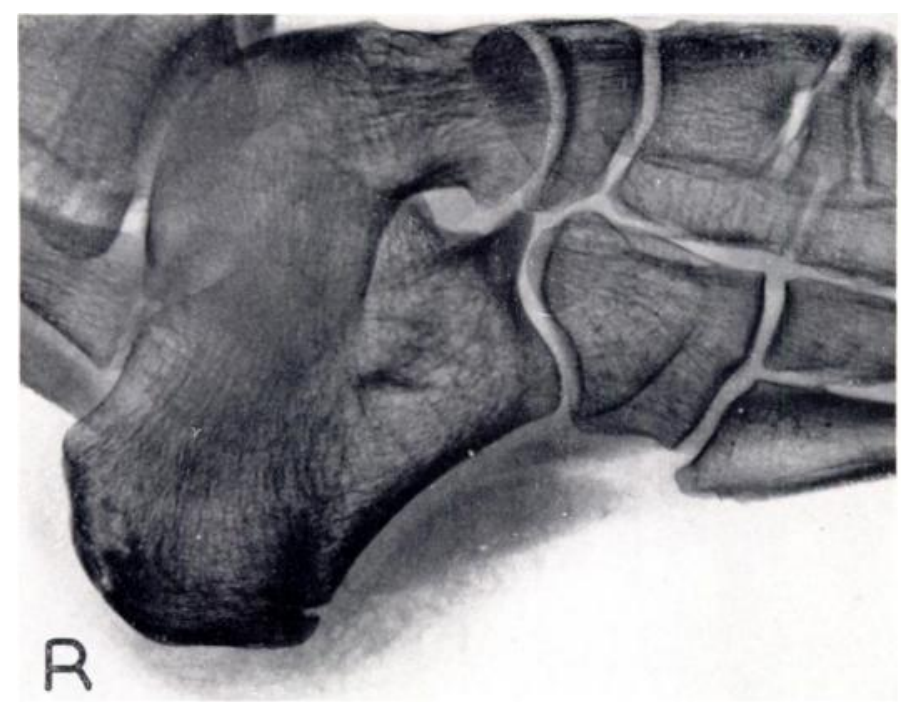

Fic. 12

Slender calcaneo-navicular bar with wide fissure in the right foot.

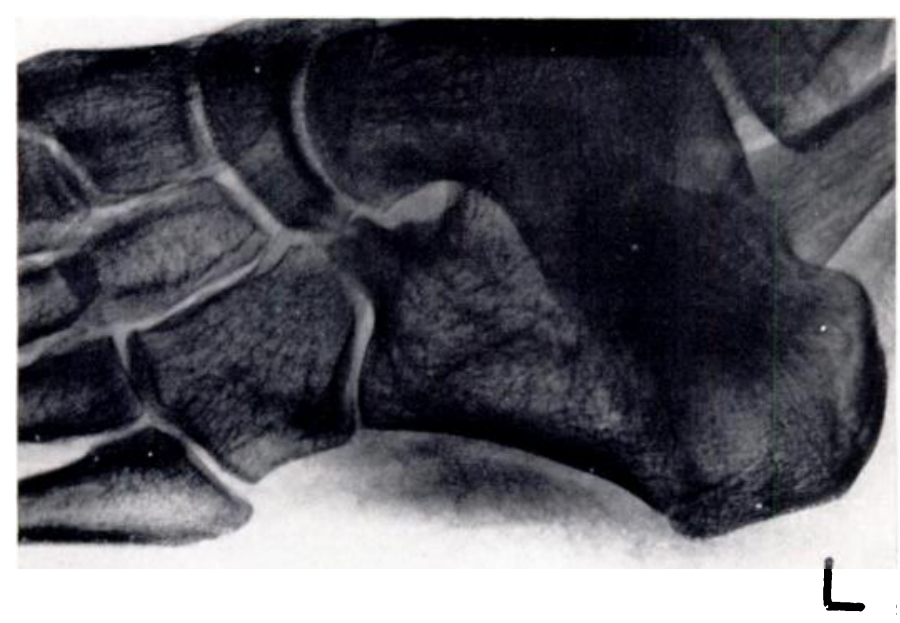

Fig. 13

.ledium-broad calcaneo-navicular bar with a narrow, well defined fissure in the left foot of the same patient.

\section{PERONEAL SPASM WITHOUT BONE ANOMALY}

There remain to be described the seven patients who reported with undoubted peroneal spasm but in whom neither of the two bony anomalies was found. Harris and Beath included only two such cases in their series, both due to rheumatoid arthritis. Webster and Roberts did not discuss this group at all. Patients with rheumatoid arthritis have been excluded 
from this series because it is felt that the condition in that disease is well known and the supply of cases almost unlimited.

One young boy of ten was observed for two years with recurrent peroneal spasm and pain; eventually it became clear that he had a tuberculous infection of the talus. Two others presented rigid everted feet some years after an atrophic arthritis of the tarsal joirts. Secondary osteoarthritis of the tarsus was the cause of the rigidity.

The remaining four patients were the most interesting. They reported between the ages of nine and fifteen with true peroneal and extensor spasm, and pain affecting one foot. In two there was a clear history of injury to the foot a short time before the onset of simptoms, and in two a reasonably definite story of occupational strain. In all four patients the spasm and pain subsided completely with rest from weight bearing followed by phrsiotherapr: Seen two years later, all had normal mobile painless feet and had made a complete recovery. As an example, a boy of fifteen left school and started in a tailor's shop where he worked a heavy treadle machine with his left foot all day long. In three months he developed serere peroneal and extensor spasm. Radiographs of the foot showed a moderate flat-foot deformity

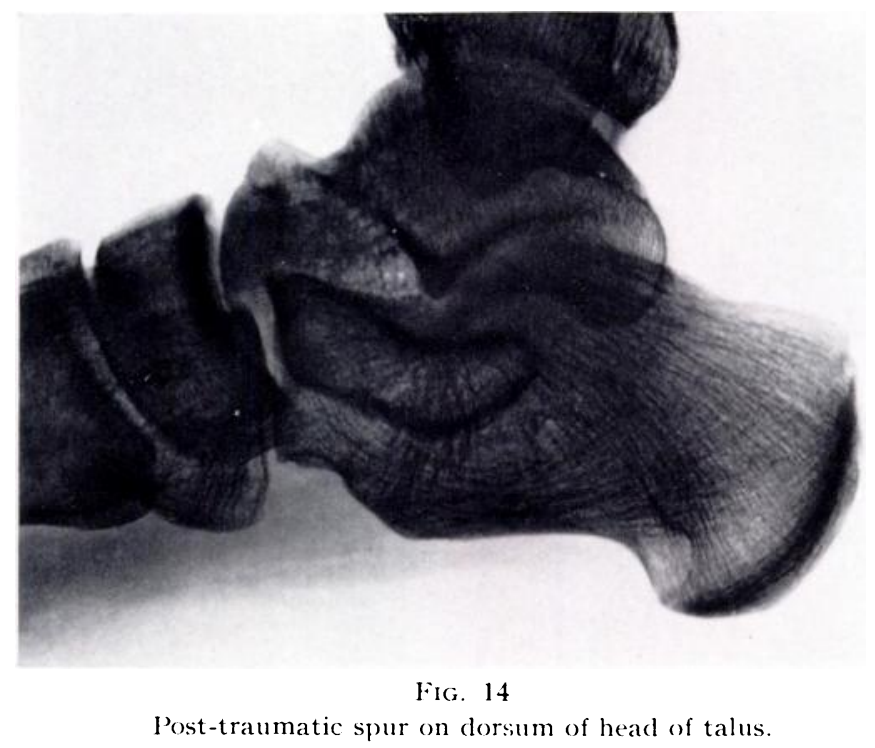

without sign of bony anomaly. After six weeks' treatment his pain and spasm cleared, leaving some stiffness in the peritalar joint. He was kept on foot exercises for two months. seen two and a half years later he was working as a miner on rough ground without any symptoms from the foot, which was fully mobile. Radiographs showed a spur on the dorsum of the talus unlike that developing with the bony anomalies, but much more like the spurs that form after tear of the capsular ligament (Fig. 14).

In these four cases the spasm was related to trauma or chronic strain of the ligaments controlling the midtarsal and subtalar joints. The mechanism of production is probably that described by Lapidus (1932, 1946). Spasm may also occur as the result of an infective lesion of the joints. Rigid flat foot may develop at a later stage from chronic irritation or degeneration in the joints.

\section{DISCUSSION}

It is appropriate at this stage to discuss some of the main clinical findings in the present series in the light of the conclusions arrived at by other authors, expecially those of Harris and Beath (1947). While there is no wish to minimise the importance of their valuable contribution-description of the talo-calcanean bridge-several of the assertions they made 
are difficult to reconcile with the facts that present themselves on clinical observation. It is easy, when one has made an original and important new discovery, to be led away by enthusiasm into inaccurate conclusions. Possibly the patients on whom they based their assertions were older than those of the present series and the series reported by Webster and Roberts (1951).

Age incidence-The first point for argument concerns the age at onset of symptoms and disability. Slomann (1921) reported one case of calcaneo-navicular bar with trouble at four vears, and four cases with symptoms beginning at ten years or over. Badgley (1927) stated that symptoms in calcaneo-navicular bar start uniformly at puberty. Webster and Roberts agreed with this view in both types of anomaly, with the reservation that some rigidity of the heel is probably present, but unnoticed, during childhood.

Harris and Beath stated that these anomalies frequently cause trouble in early childhood. They argued that because the deformity is a congenital one it must cause abnormality. They even went so far as to suggest that the anomaly is, rarely, detected before the child begins to walk, when a diagnosis of calcaneo-valgus is made, and the true lesion can be visualised by special projection. This seems a little optimistic and probably purely conjecture. No evidence is offered to support the suggestion. They also suggested that calcaneo-navicular bars might produce symptoms in early childhood.

The patients in the series reported here came from an area which is well covered by school orthopaedic services. All school children have their feet examined carefully on admission to school at the age of five and thereafter at intervals. It seems rather surprising, therefore, that if these anomalies cause symptoms early, more cases have not been seen at an earlier stage. Rigid flat foot has been a great rarity at the school clinics in children below the age of ten to eleven. The tarsus in early years is largely composed of cartilage and it is not until the age of eight or nine years that bone fills up this cartilaginous matrix. Slomann quoted Holl of Zuckerhandl's Clinic, who reported the dissection of an infant's foot in which there was a purely cartilaginous bar between calcaneum and navicular. It seems possible that this cartilage may provide sufficient resilience to permit a useful range of movement until ossification converts the bar into a rigid structure. Another interesting point is the condition of the subtalar joint in cases of talo-calcanean bridge. In the cases operated upon the main joint surfaces have possessed normal healthy articular cartilage of normal thickness. It seems doubtful whether this would be the case had the joint been rigidly fixed and functionless since birth. Nevertheless it is admitted that there is probably some restriction in the range of movement in childhood. There is an opportunity here for further useful research in observing the feet of young children with these points especially in mind.

Spasm-For years spasm has been regarded as the main feature of the disability and the term peroneal spasm or spastic flat foot has been used universally as descriptive terminology by intelligent surgeons. For a period, many followed the teaching of Sir Robert Jones in attacking the spasm directly by nerve crush or by tenotomy of tendons. Harris and Beath discounted spasm and practically denied its existence, substituting the idea of adaptive shortening of peroneal tendons. This conception is perfectly true in patients of seventeen years or more, in whom fixed eversion has become established after several years of chronic symptoms. But who is there who has not seen the youngster of thirteen or fourteen years with peroneal tendons, and long extensor tendons too, standing out like bowstrings across the foot, and the relaxation of these tendons that anaesthesia brings ? This is not adaptive shortening. It is spasm. The finding in this series agrees with that of Webster and Roberts, who found that spasm certainly occurs in the younger adolescents in acute episodes and that it subsides with rest and physiotherapy. If these attacks of spasm go untreated for any length of time they lead to rapid deterioration of the foot, because continued weight bearing on the strongly pronated forefoot soon causes a breakdown in the long arch and a more severe flat foot than would otherwise have been the case.

VOL. $36 \mathrm{~B}$, No. 4, NOVEMBER 1954 
Eversion and rigidity-The question why the foot becomes everted and rigid is not easy to answer satisfactorily for both anomalies. It is obvious why the talo-calcanean bridge causes rigidity-because the subtalar joint itself is bridged and fixed. But why should the foot

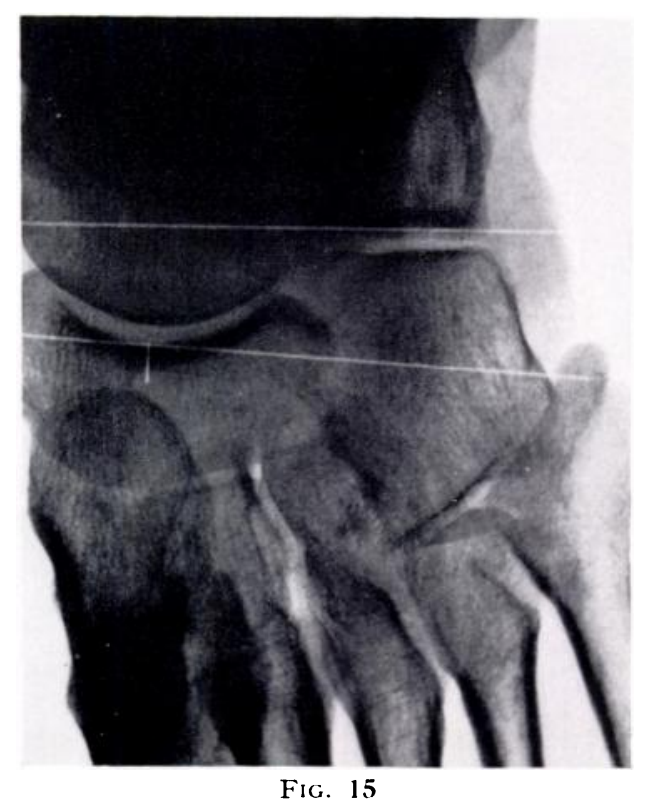

Peritalar movement. Heel everted

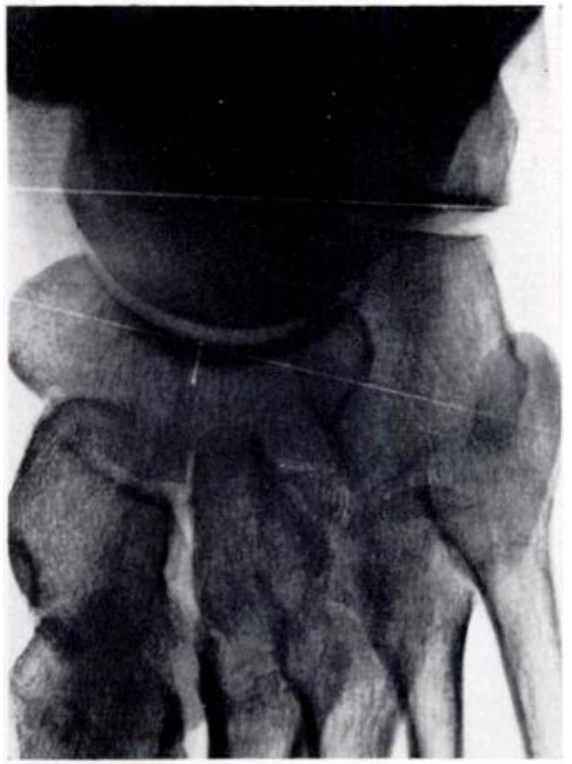

FIG. 16

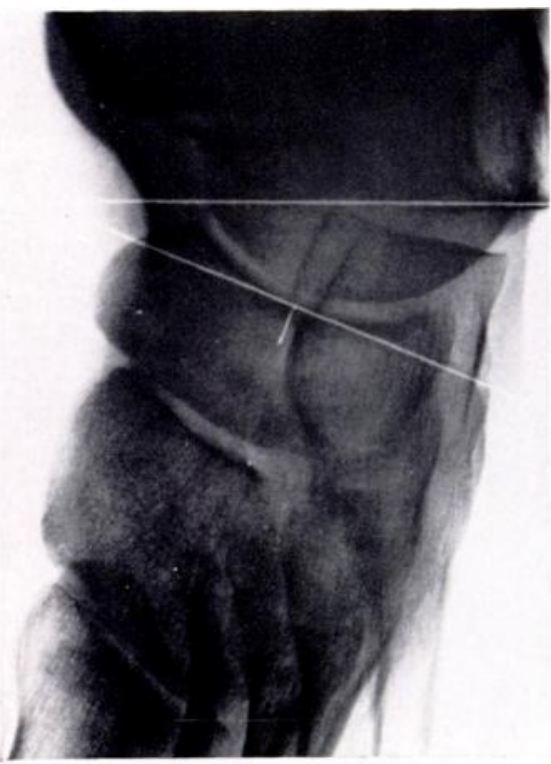

FIG. 17

Figure 16-Peritalar movement. Heel in neutral eversion-inversion. Figure 17 -Peritalar movement. Heel inverted.

become everted? Possibly the anomaly is comparable to " sacralisation " of the fifth lumbar vertebra. The case with large overgrowth not only of the transverse process but also of the side of the vertebral body, so that the fifth lumbar body is wedged laterally, is well known. 
Possibly a similar mechanism is at work in the foot. This is pure conjecture and is suggested for want of a better explanation.

In the case of the calcaneo-navicular bar the deformity and rigidity are easier to explain. Movement in the subtalar and midtarsal joint (peritalar movement) is a complex one. As pointed out previously (Jack 1953), eversion of the heel is accompanied by an inward swing of the head of the talus, so that a valgus angulation is produced at the midtarsal joint. Conversely, inversion of the heel is accompanied by varus angulation at the midtarsal joint. During these movements the transverse axis of the navicular moves in relation to the transverse axis of the anterior end of the calcaneum, through a range of 15-20 degrees (Figs. 15 to 17). This forms an essential element in peritalar movement. If the navicular is fixed to the anterior end of the calcaneum, this movement is prohibited and therefore there will be obstruction to the valgus and varus movement at the midtarsal joint, and therefore to peritalar movement. When the bar is narrow and has a wide fissure, there may be enough movement between navicular and calcaneum to allow some peritalar mobility. When the bar is large it occupies most of the lateral side of the talo-navicular joint as well as the under-surface. As ossification expands the bar, the talar head gets pushed medially into the valgus position and eversion of the heel automatically results. The larger and more complete the bar, the greater the degree of eversion and ridigity. This corresponds with the clinical findings.

\section{TREATMENT}

The management of a case seen in early adolescence has been by a policy of expectancy and symptomatic treatment. When there is no marked deformity and no spasm little may be required beyond periodic observation and the application of heel wedges to the shoes. In patients with an acute episode of spasm and pain, physical rest to the foot either in a plaster (when one foot only is involved) or by rest in bed (when both are affected) has been the policy. Manipulation under an anaesthetic and the application of a plaster in the corrected position has often been advocated, even by Harris and Beath, who have based all their other contentions on the congenital bony nature of the lesion which permits no movement. In this context the case of a patient on whom this treatment was carried out comes vividly. to mind. A girl of thirteen was seen with rigid eversion and recurrent spasm of some standing. When manipulation was performed under an anaesthetic the heel came round into the plantigrade position, to the accompaniment of cracks and rending sounds in the supposedly sticky joint capsules and ligaments. The day her plaster was removed the foot was as rigidly everted as before. Operation for triple fusion from the lateral approach revealed the subtalar joint to be firmly fixed - without a degree of movement-by a talo-calcaneal bar; and when manipulation was repeated it was seen that the talus had become partly dislocated from the tibio-fibular mortise. Since that experience, manipulation has not been attempted but plaster has been applied in the position which the foot adopts. If spasm is a prominent element, it will subside just as well from the rest imposed by the plaster, and the original degree of mobility will be regained.

In cases of longer standing, in which deformity is great or disability pronounced, fusion of subtalar and midtarsal joints has been carried out. In cases of calcaneo-navicular bar the deformity can be corrected and fusion performed through the standard lateral approach. But in the presence of a talo-calcaneal bar the operation is difficult through that incision and it has been found much easier to use the medial approach as advocated by Harris and Beath. In this way the bony block to inversion can be excised and sufficient room obtained to excise most of the main subtalar facet and sustentaculum facet, and to excise the surfaces of the talo-navicular joint. The calcaneo-cuboid joint is not fused. The five feet operated on in this way have all been satisfactory both cosmetically and functionally.

No operation to excise the calcaneo-navicular bar has been performed. To have any chance of success excision would have to be carried out very early, and it is not always easy

VOl. 36 B, No. 4, NOVEMBER 1954 
at that stage to judge what the ultimate condition of the foot is likely to be. Technically the operation is not difficult when the calcaneo-navicular bar is small, but this type often causes little subsequent trouble. The larger complete calcaneo-navicular bar is a formidable structure to excise and its removal theoretically leaves two extensive areas of raw bone in fairly close apposition. Further information on the results of this operation is required before it can be accepted as a standard method of treatment. It is obviously useless to excise the bar once rigid deformity has developed and secondary changes are present in the tarsus. Triple fusion is the only possible line then, and is usually satisfactory provided enough bone is taken away to permit full correction of the eversion and valgus.

\section{NOMENCLATURE}

Harris and Beath made a well justified plea for a review of the nomenclature in these conditions so that a more descriptive anatomical indication of the real lesion might be given. It is true that the term peroneal spastic flat foot is insufficient and fails in many ways to indicate cause and effect. It is suggested that there should be three categories. The first includes the bony anomalies. The anatomical description would cover all the various symptomatological phases: 1) talo-calcanean bridge; 2) calcaneo-navicular bar.

The second category embraces those cases without bony anomaly, in which spasm is caused by injury, inflammation, or mild infection-for example, peroneal spasm due to midtarsal trauma, peroneal spasm due to early tuberculous disease of the talus.

A third category embraces those cases seen late as rigid flat feet, and due to a variety of causes-arthritic, rheumatoid, old infection, etc.; for example, rigid flat foot due to atrophic arthritis. This last group does not include rigid flat feet from old established bars or bridges which are grouped in the first category.

\section{SUMMARY}

1. Twenty-three cases of tarsal anomaly-talo-calcaneal bridge or calcaneo-navicular baroccurring among thirty cases of " peroneal spastic flat foot" have been studied.

2. The correlation between the clinical features and the mechanical defect is discussed.

\section{REFERENCES}

BAdGLEy, C. E. (1927): Coalition of the Calcaneus and the Navicular. Archives of Surgery, 15, 75.

Harris, R. I., and Beath, T. (1947): Army Foot Survey: an Investigation of Foot Ailments in Canadian Soldiers. Ottawa: National Research Council of Canada. Report No. 1574.

JACK, E. A. (1953) : Naviculo-Cuneiform Fusion in the Treatment of Flat Foot. Journal of Bone and Joint Surgery, 35-B, 75.

JonES, Sir Robert (Ed.) (1921): Orthopaedic Surgery of Injuries. Two vols. London: Oxford University Press.

Lapidus, P. W. (1932): Congenital Fusion of the Bones of the Foot; with a Report of a Case of Congenital Astragaloscaphoid Fusion. Journal of Bone and Joint Surgery, 14, 888.

LAPIDUS, P. W. (1946): Spastic Flat-Foot. Journal of Bone and Joint Surgery, 28, 126.

Magee, R. K., and Benson, R. A. (1946): Calcaneo-Scaphoid Bar. Canadian Medical Association Journal, N.S. 55, 287.

Slomann (1921): On Coalitio Calcaneo-Navicularis. Journal of Orthopaedic Surgery, N.S. 3, 586.

Webster, F. S., and Roberts, W. M. (1951): Tarsal Anomalies and Peroneal Spastic Flatfoot. Journal of the American Medical Association, 146, 1,099. 